\title{
Organ Donation in an African Culture
}

\author{
Ayinde Jamiu Kunle \\ Department of Philosophy, Olabisi Onabanjo University, Ago Iwoye, Ogun State, \\ ayindejamiu90@gmail.com
}

\begin{abstract}
This paper is an attempt to examine the traditional Yoruba beliefs about organs donation. Organ donation and transplantation remain a rare occurrence in Africa, this to a large extent can be as a result of the traditional African orientation on one hand and the advancement in medical research that came with transplanting organs on the other. This paper x-rays the problem of organ shortages in most African countries. It noted that apart from lack of awareness on organ donation, Africans traditionally would not be willing to donate their organs after death. This paper critically examines beliefs in some African cultures and their relationship with organ donation. We analyze life after death in the Yoruba tradition and the belief in the continuation of the body after death. The paper concludes that African belief in the continuation(reincarnation) of the body in the afterlife contributes to their non-willingness to donate an organ after death.
\end{abstract}

Key words: Organ donation, African culture, Yoruba culture

Introduction: Organ transplantation is one of the recent medical solutions to organ failures. Before 1950, the failure of an organ is almost equivalent to a death sentence. Today, research in the medical field brought about organ transplantation to solve the problem of organ failures. Rainer Gruessner (2016) defines organ donation as "the act of giving one or more organs (or part thereof), without compensation, for transplantation into someone else". However, the availability of organs for transplantation remains challenging since the discovery of organ transplants. Babara (2004) said:

Ever since the first transplants were carried out in the 1950s, there has been an imbalance between the availability of donated organs and the number of recipients.

Razek et al buttress this point when they said:

Greater knowledge and technical advances in the field of transplantation have increased the demand for organ donationbeyond the current capacity to supply them. For example, the transplant waiting list in the United States in 1999 was 65793 patients growing at an average rate of $16 \%$ per year as against the cadaveric increase of 5.6\% in 1998 (Razek, Olthoff \& Reilly, 2000).

A Major ethical issue in organ transplantation today arises in the process of generating organs for transplantation. There are four major processes of generating organs for transplant. The first is livingorgan donation. This is a process where an is organ generated from donors who are still alive. It can be family, relatives, friends or strangers. Livingdonors are classified as the givers of life. They are not selfish with their body organs. They will that someone else who is dying can benefit from the unused or unimportant organ in their body. Such living donor donates an organ that does not cease life. An example of an organ donated by a living donor is the kidney, where one of the two kidneys possessed is donated to 
someone who has kidney failure. Dunstan (1997) has this to say:

With transplantation from living donors the notion of 'donation', 'gift', becomes a reality: a willed, conscious gift. It extends from the giving of expendable or renewable resources like blood, bone marrow, and neural stem cells, to paired organs, kidneys, and segments of single organs, liver, spleen, and lung. It can save lives and improve the quality of lives, and so it can exert its emotional appeal directly on the potential donor

Some ethical issues arise from living donors. One of such is the sales of organs. It is the opinion in some quarters that the gift of an organ is a "gift that kills".

Another way of generating organs for transplantation is called xenotransplantation. This is the process of generating organs from animals. This process raises some ethical issues. Animal rights ethics frown at using the animal organ to cure human beings. However, the research in this aspect has not been perfected.

Advance research in medical ethics has also brought about technological solutions to generating organs. There are several approaches to generating organs without considering natural existing organs. Regenerative medicine remains a prominent advanced medical research where organs are generated technologically from the stem cell of the patient in need of the organ. This process is yet to be perfected and there are only a few successes recorded in using advanced medical research in solving the problem of organ donation.

Organs generated from cadaveric donors provided a major solution to the problem of organs shortage. Cadaveric organ donors can donate a more useful organ to cure the patient on the waiting list. The major challenge of generating organs through cadavers is the consent of both the cadaver and the family of the cadaver. The discussion on consent leads to the issue of autonomy. It has been argued that every individual has autonomy over his body, if such a body should be used after the death of the person, such person's consent should be sorted.

Generating organs from cadaveric donors requires educating the masses and government providing policy on how consent will be given by the citizen on organ donation. Government policy on organ donation consent can fall into one of these three categories. Presume consent, which is the assumption that the citizens will approve their organ to be donated for a patient in need of such organs. The policy only allows people who are not willing to opt-out by either signing a document or notifying a center of not agreeing with such presumption. The policy assumes that everyone would be willing to donate an organ. Presumed consent is defined according to the Medical dictionary as the assumption that a particular action would have been approved by a person or party if permission has been sought. Daniel also has this to say about presume consent.

Presumed consent is also referred to as the "opt-out" system because individuals would have the option of opting out of the system and not donating their organs. (Daniel: 7)

The second policy option is called presumed refusal where the government assumes that people are not willing to donate an organ. The policy gives room for those who wish their organ to be donated after death to sign a document or put down their wiliness in a program record. 
The third of the organ donation consent policy is a mandated choice which mandates every living person to take a position without any assumption.

No doubt organ failure is a phenomenon that occurs in all countries either third world countries or first world. Today, organ failure treatment in Africa is giving low attention. Even though crowd funding is the launch, a very few African are willing to donate their organs after death. Most African country till date don't have organ bank nor do they have a waiting list of patients in need of organ transplant. Some traditional African beliefs do not give room to exercise a gift of life.

Africans and Organs Donation: The tripartite belief in the nature of human being as constituting the body, soul and mind also exists in Africa. However, the belief that when death occurs, the body becomes useless and separated from the soul seems not to be in consonance with African belief about the body after death.

Most Africans believe that there is life after death, however such life which they usually refer to as the ancestral world requires them to have a good body and soul. Africans believe that when someone dies in a mysterious way, or not buried properly with all his or her body intact, such a person would not be accepted by ancestors or as ancestor in the life after death.

On this, Thembelihle Ggogqoni, an elderly community member and also a traditional healer averse that, it is against black culture to remove the organs of a deceased person as it is believed their spirit continues to roam and will not be accepted by ancestors.
The completeness of the body and proper burial has a relationship with the acceptability of the spirit of such a person in the life after. The way Africans respect their body and spirit while alive is the same way the body and spirit are respected after death. The body needs to be accorded adequate respect and put in good condition so that the spirit of the deceased will be accepted by the ancestors. Thembelihle further posits:

As a traditional healer, I have a strong belief in the existence of ancestors and I directly communicate with them. If I die and have missing organs I will not be accepted by my ancestors. The body of the deceased has to be treated with respect

The belief that body and soul need to be intact for the soul to be accepted by the ancestors affects the traditional African community's orientation on organ donation. Organ donation will remain alien to traditional Africa belief as it cannot exist alongside the belief of body usefulness in life after death. On this ZizoZikali said:

While thousands of South Africans are currently waiting for a life-saving organ transplant, it remains a difficult task to convince rural black communities to donate organs because of their cultural beliefs.

The attitude of Africans towards organ donation will remain low as long as the cultural belief is considered. Traditionally, Africans will not be willing to donate an organ. When we consider the responses, we get from rural communities in African as regard organ donation, we will realize that cultural belief has grossly affected the willingness to donate an organ by traditional African. Mr Ngurewa Mwachofi, an expert in social behavior and communication, says religious and cultural beliefs are to blame for the negative attitude towards organ donation. 
It is this belief that prevents Africans from donating their corneas to patients in need. Mr. Ngurewa further said base on his experience in Africa that:

We'd like them to pledge their corneas but because of their religious beliefs, they say they have to see heaven. Still, we've tried to talk to them to donate their corneas so they can help someone see this world.

The major argument for organ donation is convincing the donor the fact that what he or she intends to donate is not useful to him or her but to the patient that is in dire need of it. In the area of a cadaveric donor, the argument remains that the dead is no longer in need of the body vis a vis the kidney, bone marrow, liver among others.

Etheredge et al rightly identified the reason for the decrease in the willingness of Africans to donate an organ in their research on organ donation when they say:

A decrease in willingness to donate heart, liver, and corneas was expressed by the black African population. This is consistent with cultural beliefs that emphasize the role of the ancestors after death, and the notion that the body should remain intact for spiritual reasons.

However, the traditional Africa belief that such body is very much needed by the donor, it is a necessary condition for the donor to be accepted to the ancestral world.

In the other examples that were given, the traditionally society believes that if cornea was donated to a patient the donor will not see heaven. This shows that it is only when traditional beliefs about body uselessness after death are resolved, that is when we will have more traditional Africans ready to donate organs to the patients in need of it.
Yoruba and After World: Yoruba culture as one of the traditional Africa culture is not exempted from the belief in the usefulness of the body in the ancestral world. The Yoruba believe that the body needs to be intact for the ancestors to accept such a person into their world.

The belief in the fusion of the body and the soul in the Yoruba belief system can be seen in their understanding of Abiku. The Yoruba believe that Abiku can be prevented from coming back by defacing the body of the dead child. This belief also leads them to the belief that if such a child is to be given birth to again, the mark of the defaced part will appear in the child's body. This is explained by Umpire Abey when he posits about the Yoruba on Abiku that:

Owing to the ephemeral nature of Abiku's life, Abiku completes several consecutive life-cycles with one mother. In some reality cases, the Yorubas, in one of their traditional ways of deterring Abiku from death after reborn deface such children either by cutting their finger, ear or a deep mark in the face or back. To a great surprise in most cases, the Abiku on reborn would have those marks whether on the face or back.

This shows that the body and the soul have some fundamental relationship and that relationship does not end at death.

The Yoruba just like other traditional Africa belief does not accommodate organ donation. Although Africans are communitarian in nature, they don't believe that the body is part of their property that they can give away. The body is a necessary condition for living while alive as well as a necessary condition for acceptability in the ancestral world. 
Conclusion: This paper concludes that owing to the African belief system of life after death, organ donation cannot be successful in the traditional Africa community. This paper raises a new dimension to the discussion on community acceptance of organ donation. Traditional Africa will rather prefer adequate efforts to perfect the advance medical research in donating organs through regenerative medicine rather than calling on the people to donate an organ for the patient on the waiting list.

The apathy to organ donation experience in African is not only a result of lack of awareness or education, but the traditional African belief also contributes to the dearth of organs availability.

\section{Reference:}

Barbara K Pierscionek. What is presumed when we presume consent? BMC Medical Ethics, 2008; 9:8

Anonymous. The Yoruba Concept of Abiku and Emere In Yorubaland.

http://www.ekimogundescendant.org/the-yorubaconcept-of-abiku-and-emere-in-yorubaland/ (Access on July 2018)

Anne Soy. Why is organ donation taboo for many Africans? BBC Africa, Nairobi 2015. https://www.bbc.com/news/world-africa-31350463 (Access on 10 February 2018)

Zizo Zikali. Cultural beliefs discourage organ donors. Health news 3rd January 2018. https://www.healthe.org.za/2018/01/03/cultural-beliefs-discourageorgan-donors/ (Access on 10 February 2018)

Daniel, S. “Organ Donation: Autonomy, Presumed Consent, and Mandated Choice". Oakland University 2016. http://www.oakland.edu/upload/docs/Philosoph y/Springer_Essay.pdf(Access on 10 February 2018).

Dunstan G. R., The Ethics of Organ Donation in British Medical Bulletin 1997: 53:4:
Etheredge H. R, R. E. Turner and D. Khan, Attitudes to Organ Donation among some urban South African Populations remain unchanged: A cross-sectional study (1993 - 2013) in SAMJ 2014; 104,: 2.

Rainer, G. (2016). "Organ Donation", Available at $<$ http://www.britannica.com/topic/organ-donation $>$ (Accessed on 30th of January, 2018)

Razek, T, Olthoff, K \& Reilly P. Issues in Potential Organ Donor Management. Surgical Clinics of North America 2000; 80:(3):1021 - 1030.

Author declaration: The Author conceived the idea, did the literature review and wrote the manuscript. He also checked the manuscript meticulously.

Conflict of interest: No Conflict of Interest. 